\title{
KINERJA PEGAWAI OUTSOURCING DI PT. TELKOM DIVRE VII KOTA MAKASSAR
}

\author{
Akhmad Harye Sumitra Ishak ${ }^{1}$, Abd Kadir Adys $^{2}$, Haerana $^{3}$ \\ 1) Jurusan Ilmu Administrasi Negara Unismuh Makassar \\ 2) Jurusan Ilmu Administrasi Negara Unismuh Makassar \\ 3) Jurusan Ilmu Administrasi Negara Unismuh Makassar
}

\begin{abstract}
The purpose of this research was to explain the performance of outsourcing employees in the office of PT. Telkom Divre VII Makassar City. The informants in this research consisted of 8 people. The type of research used was phenomenology and data analysis used was a qualitative description by selecting certain people who are considered capable of providing information related to employee performance in the office PT. Telkom Divre VII Makassar City. The data collection techniques used by researchers are interview, observation, and documentation. The results of the research showed that there are five factors that become the basis for managing the performance of the outsourcing employee. The five factors are quality of work, timeliness, initiative, ability and communication in PT. Telkom as a measure of performance for all employees. Based on the results of research at the office of PT. Telkom City Access Makassar regarding employee performance is still good seen from the work of each employee based on the procedures that have been set by the company.
\end{abstract}

Keywords : Performance, Outsourcing Employees, PT. Telkom Divre VII Makassar.

\begin{abstract}
ABSTRAK
Tujuan penelitian ini untuk menjelaskan kinerja pegawai outsourcing di kantor PT. Telkom Divre VII Kota Makassar. Jumlah informan dalam penelitian ini adalah 8 orang. Jenis penelitian yang digunakan adalah fenomenologi dan analisis data yang digunakan adalah deskripsi kualitatif dengan memilih orang tertentu yang dianggap mampu memberikan informasi terkait kinerja pegawai di kantor PT. Telkom Divre VII Kota Makassar. Teknik pengumpulan data yang digunakan peneliti adalah wawancara, observasi, dan dokumentasi. Hasil penelitian menunjukkan, terdapat lima faktor yang menjadi dasar dalam manajemen kinerja pegawai outsourcing. Kelima faktor tersebut adalah kualitas kerja, ketepatan waktu, inisiatif, kemampuan dan komunikasi yang ada di kantor PT. Telkom tersebut sebagai alat ukur kinerja seluruh pegawai yang ada terkhusus pegawai outsourcing. Berdasarkan hasil penelitian di Kantor PT. Telkom Akses Divre VII Kota Makassar mengenai kinerja pegawai masih baik di lihat dari hasil kerja setiap pegawai berdasarkan prosedur yang sudah di tetapkan oleh perusahaan.
\end{abstract}

Kata Kunci : Kinerja, Pegawai Outsourcing, PT. Telkom Divre VII Makassar 


\section{PENDAHULUAN}

Perlindungan hukum adalah pemenuhan terhadap hak-hak dasar yang melekat diatur dalam konstitusi tertuang pada Pasal 27 ayat (2) UUD Tahun 1945 berbunyi "Tiap-tiap warga Negara berhak atas pekerjaan dan penghidupan yang layak bagi kemanusiaan", dan Pasal 33 ayat (1) yang menyatakan bahwa 'Perekonomian menupakan suatu usaha bersama atas kekeluargaan". Pelanggaran akan hak dasar merupakan pelanggaran hak asasi manusia (HAM) yang telah diatur oleh konstitusi.

Menjamin hak-hak dasar dan perlakuan tanpa diskriminasi pekerja diterapkan peraturan perundang-undangan perlindungan bagi pekerja yaitu UU No. 13 Tahun 2003 Tentang Ketenagakerjaan serta Peraturan Pelaksana dari perundang-undangan di bidang Ketenagakerjaan. Dalam mewujudkan peningkatan kesejahteraan pekerja maupun keluarganya.

Kendala dalam hal ketenagakerjaan di Indonesia yakni adanya ketidak seimbangan di antara pengusaha maupun bunuh dalam konsep perjanjian kerja mengakibatkan iklim persaingan usaha semakin ketat sehingga mengakibatkan perusahaan harus mengambil kebijakan efisiensi biaya produksi (cost of production). System outsourcing ialah salah satu solusi dalam menghemat pengeluaran biaya sumber daya manusia sebuah perusahaan. Dalam hal ini outsourcing merupakan pendelegasian dalam proses bisnis, dimana terjadi proses administrasi dan manajemen oleh pihak penyedia jasa sesuai dengan kriteria yang di inginkan perusahaan.

Outsourcing (AlihDaya) pada hukum ketenagakerjaan diatur dalam UU ketenagakerjaan No. 13 tahun 2003 (pasal 64, 65 dan 66) serta Keputusan Menteri Tenaga Kerja Dan Transmigrasi Republik Indonesia No. Kep.101/Men/VI/ 2004 Tahun 2004 tentang Tata Cara Perizinan Perusahaan Penyedia Jasa Pekerja/Buruh (Kepmen 101/2004). Dalam hal ini pemerintah menugaskan menteri tenaga kerja agar melakukan revisi terhadap UU No. 13 Tahun $2003 \quad$ Tentang Ketenagakerjaan.

Hubungan kerja merupakan suatu sistem yang mengambarkan adanya ikatan pada buruh maupun majikan dengan memberikan pemahaman tentang hak-hak dan kewajiban buruh pada majikan, begitu pula dengan hak dan kewajiban kepada para buruh. Dalam 
Kolaborasi: Jurnal Administrasi Publik, Desember 2018 Volume 4 Nomor 3

hal ini banyak perusahaan yang menggunakan tenaga outsourcing untuk dapat melakukan efisiensi biaya tenaga kerja.

Adapun hal-hal yang perlu menjadi perhatian khusus di sini antara lain, jenjang karir yang tidak jelas. Para pegawai outsourcing hanya bersifat kontrak, maksudnya apabila waktu kontrak mereka telah selesai tidak ada jaminan mereka masih berada dalam suatu perusahaan tersebut. Kemudian yang menjadi acuan setiap perusahaan ialah kinerja para pegawainya. Pegawai yang memiliki kinerja bagus tentunya akan dipertahankan, namun sebaliknya ketika kinerja mereka buruk maka akan di lakukan mutasi yakni dikeluarkan dari perusahaan tersebut karena bersifat kontrak.

Selain jenjang karir yang tidak jelas, intensif yang diterima (upah) juga merupakan kendala pada kinerja para pegawai outsourcing. Mereka beranggapan bahwa upah tersebut sudah tidak sesuai dengan situasi perekonomian saat ini. Sehingga kelayakan pemberian intensif menjadi suatu hal yang tentunya akan menunjang kinerja pegawai outsourcing itu sendiri. Kemudian beban pekerjaan para pegawai outsourcing cenderung lebih banyak dan tergolongan berat. Hal tesebut tentunya menjadi salah satu problematika aktifitas pekerjaan yang di laksanakannya. Tentu sangat miris ketika kita melihat realita yang terjadi saat ini khususnya pegawai outsourcing di PT. Telkom Divre VII Makassar. Adanya kesenjangan pada pegawai outsourcing tentu akan berpengaruh pada kinerja pegawai. Dimana kita perlu mengetahui yakni pegawai outsourcing adalah alat ujung tombak perusahaan dalam pencapaian tujuan atau penentuan hasil dari perusahaan.

Menunut Lebas \& Euske (2008) Kinerja merupakan sesuatu yang dapat diukur, baik diukur menggunakan angka atau menggunakan sebuah ekspresi yang memungkinkan terjadinya komunikasi. Kinerja adalah kemampuan untuk menghasilkan atau potensi untuk menciptakan hasil (sebagai contoh, kepuasan pelanggan bisa dilihat sebagai potensi bagi organisasi untuk menciptakan penjualan pada jangka waktu yang panjang).

Armstrong \& Baron (2010: 158) kinerja merupakan proses akan kontribusi terhadap 
efektivitas manajemen individu dan tim untuk mencapai kinerja organisasi pada level yang sangat tinggi dalam memberikan hasil yang memuaskan sesuai dengan visi misi yang di sepakati secara bersama. Demikian juga kinerja sering dianggap sebagai konstruk multidimensi (Bates \& Holton, 2009) yang tidak hanya dikaitkan dengan keseluruhan organisasi tetapi juga dengan bagian-bagian dalam organisasi termasuk unit aktivitas, proses dan individu karyawan. Karena itulah sangat tidak mengherankan jika kinerja didefinisikan secara beragam. Untuk memahami pengertian kinerja, kiranya perlu terlebih dahulu memahami arti kata kinerja secara harfiah.

Istilah outsourcing diartikan sebagai contract (work) out. Menurut Maurice Greaver, outsourcing merupakan tindakan mengalih beberapa aktivitas perusahaan serta hak pengambilan keputusannya kepada pihak lain (outside provider), dimana tindakan ini terikat pada suatu kontrak kerja sama. Boleh juga dikatakan outsourcing merupakan penyerahan kegiatan perusahaan secara menyeluruh kepada pihak lain yang tertuang pada kontrak perjanjian. outsourcing dapat dilihat pada ketentuan Pasal 64 Undang-Undang Nomor 13 Tahun 2003 tentang Ketenagakerjaan, yang isinya menyatakan adanya suatu perjanjian kerja antara perusahaan dengan tenaga kerja, dimana perusahaan tersebut boleh menyerahkan sebagian pelaksanaan pekerjaan oleh perusahaan lainnya melalui perjanjian pemborongan pekerjaan yang telah dibuat secara tertulis.

\section{METODE PENELITIAN}

Penelitian ini dilaksanakan di kantor di kantor PT. Telkom Divre VII Kota Makassar. Penelitian ini akan dilakukan kurang lebih selama 2 bulan, yaitu Juni sampai dengan Agustus 2018. Desain penelitian dengan pendekatan kualitatif memberikan keuntungan pada kecepatan pengumpulan data. Hal ini dimanfaatkan peneliti agar dapat berfokus melaksanakannya dalam waktu yang seefisien mungkin.

Jenis Penelitian yang di gunakan adalah kualitatif yaitu metode penelitian yang digunakan adalah penekanan pada observasi wawancara untuk 
orang, sebagai lawannya adalah gambaran kondisi objektif secara ilmiah.

Penulis menggunakan tipe penelitian deskriptif dengan pendekatan kualitatif. Menurut Sugiyono 2014 penelitian kualitatif adalah penelitian yang pemecahan masalahnya dengan menggunakan data empiris.

Sumber Data: 1) Data primer, dalam penelitian ini, data primer diperoleh dari lapangan penelitian, baik pengamatan langsung maupun wawancara kepada informan. Yang dalam hal ini peneliti menggunakan teknik Expert Sampling (sampel ahli) dalam menentukan informan. 2) Data sekunder Peneliti dalam hal ini turut memerlukan data-data pendukung lain atau data sekunder untuk menguji mendukung kebenaran dari data primer yang diperoleh peneliti. Data sekunder ini dapat berupa naskah, dokumen resmi, literatur, artikel, koran dan sebagainya yang berkenaan dengan penelitian ini.

\section{HASIL PEMBAHASAN}

PT. Telkom Indonesia (Tbk) Group, menjadi satu-satunya BUMN telekomunikasi serta penyelenggara layanan telekomunikasi dan jaringan terbesar di Indonesia. Telkom Group melayani jutaan pelanggang di seluruh Indonesia dengan rangkaian lengkap layanan telekomunikasi yang mencakup sambungan telepon kabel tidak bergerak dan telepon nirkabel tidak bergerak, komunikasi seluler, layanan jaringan dan interkoneksi serta layanan internet dan komunikasi data. Telkom Group juga menyediakan berbagai layanan di bidang informasi, media dan edutainment, termasuk cloud-based and server-based managed services, layanan ePayment dan IT enabler, e-Commerce dan layanan portal lainnya.

Telekomunikasi merupakan bagian bisnis utama Telkom. Sebagai ikon bisnis perusahaan, Telkom melayani sambungan telepon kabel tidak bergerak Plain Ordinary Telephone Service (POTS), telepon nirkabel tidak bergerak, layanan komunikasi data, broadband, satelit, penyewaan jaringan dan interkoneksi, serta telepon seluler yang dilayani oleh Anak Perusahaan Telkomsel. Layanan telekomunikasi Telkom telah menjangkau 
Kolaborasi: Jurnal Administrasi Publik, Desember 2018 Volume 4 Nomor 3

beragam segmen pasar mulai dari pelanggan individu sampai dengan Usaha Kecil dan Menengah (UKM) serta korporasi.

Layanan informasi merupakan model bisnis yang dikembangkan Telkom dalam ranah New Economy Business (NEB). Layanan ini memiliki karakteristik sebagai layanan terintegrasi bagi kemudahan proses kerja dan transaksi yang mencakup Value Added Services (VAS) dan ManagedApplication/IT Outsourcing (ITO), e-Payment dan IT enabler Services (IteS).

Media merupakan salah satu model bisnis Telkom yang dikembangkan sebagai bagian dari NEB. Layanan media ini menawarkan Free To Air (FTA) dan Pay TV untuk gaya hidup digital yang modern.

Edutainment menjadi salah satu layanan andalan dalam model bisnis NEB Telkom dengan menargetkan segmen pasar anak muda. Telkom menawarkan beragam layanan di antaranya Ring Back Tone (RBT), SMS Content, portal dan lainlain. Services menjadi salah satu model bisnis Telkom yang berorientasi kepada pelanggan. Ini sejalan dengan Customer Portofolio Telkom kepada pelanggan Personal, Consumer/Home, SME, Enterprise, $\quad$ Wholesale, dan International. Sebagai perusahaan telekomunikasi, Telkom Group terus mengupayakan inovasi di ember-sektor selain telekomunikasi, serta membangun sinergi di antara seluruh produk, layanan dan solusi, dari bisnis legacy sampai New Wave Business. Untuk meningkatkan business value, pada tahun 2012 Telkom Group mengubah portofolio bisnisnya menjadi TIMES (Telecommunication, Information, Media Edutainment and Service). Untuk menjalankan portofolio bisnisnya, Telkom Group.

Memiliki empat anak perusahaan, yakni PT. Telekomunikasi Indonesia Selular (Telkomsel), PT. Telekomunikasi Indonesia International (Telin), PT. Telkom Metra dan PT. Daya Mitra Telekomunikasi (Mitratel).

Penjelasan dari visi dan misi perusahaan. Visi yakni menjadi perusahaan yang unggul dalam penyelenggaraan Telecommunication, Information, Media, 
Edutainment dan Services (TIMES) di kawasan regional. Dimana PT. Telkom Divre VII Kota Makassar merupakan perusahaan yang menyediakan layanan telekomunikasi bagi masyarakat kota makassar. Banyaknya permintaan masyarakat terhadap penyediaan alat komunikasi dan pemasangan wifi akan menjadi tanggung jawab besar bagi telkom sebagai perusahaan tunggal yang memegang jasa telekomunikasi di Kota Makassar.

Misi adalah rumusan umum mengenai upaya-upaya yang akan dilaksanakan untuk mewujudkan visi. Misi dari PT. Telkom Divre VII Kota Makassar ialah 1.) Menyediakan layanan TIMES yang berkualitas tinggi dengan harga yang kompetitif. 2.) Menjadi model pengelolaan korporasi terbaik di Indonesia.

Serta Inisiatif Strategis yaitu : 1) Pusat Keunggulan. 2.) Menyelaraskan struktur bisnis dan pengelolaan portofolio. 3.) Percepatan implementasi broad band melalui layanan konvergen. 4.) Pengelolaan portofolio nirkabel 5.)Mengintegrasikan solusi ekosistem Telkom Group. 6.) Berinvestasi dilayanan teknologi informasi. 7.) Berinvestasi dibisnis media dan edutainment. 8.) Berinvestasi dibisnis wholesale dan peluang bisnis internasional yang strategis. 9.) Memaksimalkan nilai embe di bisnis yang saling terkait. 10.) Mengintegrasikan Next Generation Network (NGN) dan Operational support system, Business support system, Customer support system and Enterprise relations management (OBCE) untuk mencapai penyempurnaan beban biaya.

Organisasi merupakan struktur tata pembagian kerja dan struktur tata hubungan kerja antar kelompok pemegang posisi yang bekerja sama secara bersama-sama untuk mencapai tujuan bersama. Oleh karena itu, perlunya struktur organisasi di dalam suatu organisasi adalah untuk memberikan gambaran yang jelas tentang kedudukan tiap-tiap personil, tugastugas yang harus dilaksanakan serta wewenang dan tanggung jawabnya. Untuk membatasi penelitian ini, penulis hanya mengambil susunan organisasi Sub PT.Telkom Akses Divre VII Kota Makassar. 
Kolaborasi: Jurnal Administrasi Publik, Desember 2018 Volume 4 Nomor 3

Unit-unit Bisnis Telkom terdiri dari Divisi, Centre, Yayasan dan Anak perusahaan, sebagai berikut : 1.) Divisi Long Distance Sub Divisi Satelit. 2.) Carrier \& Interconnection Service Center 3.) Divisi Multimedia 4.) Divisi Fixed Wireless. 5.) Enterprise Service Center 6.) Customer Service Wilayah Sumatera. 7.) Customer Service Wilayah Jakarta (Jadebotabek \& Sekapur). 8.) Customer Service Wilayah Jawa Barat. 9.) Customer Service Wilayah Jawa Tengah dan Yogyakarta. 10.) Customer Service Wilayah Jawa Timur. 11.) Customer Service Wilayah Kalimantan. 12.) Customer Service Kawasan Timur Indonesia. 13.) Maintenance Service Center. 14.) Training Center. 15.) Carrier Development Support Center. 16.) Management Consulting Center. 17.) Construction Center. 18.) I/S Center. 19.) R\&D Center. 20.) SME Development Center.

Yayasan-Yayasan terdiri dari 1.) Dana Pensiun (Dapentel). 2.) Yayasan Pendidikan. 3.) Yayasan Kesehatan. Dimana ketiga yayasan telkom merupakan sumber penghasilan lain yang di miliki PT. Telkom Divre VII Kota Makassar.
Anak Perusahaan Telkom terdiri dari Kepemilikan > 50\% yakni : 1.) PT. Telekomunikasi Selular (Telkomsel) dan Telekomunikasi (Selular GSM) (baru). 2.) PT. Dayamitra Telekomunikasi (Dayamitra) dan Telekomunikasi (KSO-VIKalimantan).

3.) PT. Infomedia Nusantara (Infomedia) dan Layanan Informasi (baru). 4.) PT. Telekomunikasi Selular Raya (Telesera) dan Telekomunikasi (Selular AMPS). 5.) PT. Pro Infokom Indonesia (PII) dan B2B (eGovernment) 6.) PT. Indonusa Telemedia (Indonusa) dan TV Cable (baru). 7.) PT. Graha Sarana Duta (GSD): Properti, Konstruksi dan Jasa.

Kepemilikan saham Telkom 20\% $50 \%$ yakni : 1.) PT. Pasifik Satelit Nusantara (PSN) dan Transponder Satelit dan Komunikasi. 2.) PT. Multimedia Nusantara (Metra) dan Multimedia. 3.) PT. Citra Sari Makmur (CSM) dan VSAT. 4.) PT. Menara Jakarta dan Multimedia. 5.) PT. Metro Selular Indonesia (Metrosel) dan Telekomunikasi (Selular AMPS). 6.) PT. Mobile Selular Indonesia (Mobisel) dan Telekomunikasi (Selular NMT-450). 7.) PT. Napsindo Primatel 
Internasional (Napsindo) dan Network Access Point. 8.) PT. Patra Telekomunikasi Indonesia (Patrakom) dan Layanan Satelit Komunikasi Industri Perminyakan. 9.) PT. Pramindo Ikat Nusantara dan Telekomunikasi (KSO-1 Sumatera).

Kepemilikan saham telkom dibawah 20\% yakni: 1.) PT. Batam Bintan Telekomunikasi (Babintel) dan Telekomunikasi (Pulau di Batam \& Bintan) 2.) PT. Komunikasi Selular Indonesia (Komselindo) dan Telekomunikasi (Selular AMPS). 3.) PT. Medianusa PTE, Ltd dan Agen Penjualan Buku Petunjuk Telepon (BPT). 4.) PT. Pembangunan Telekomunikasi Indonesia (Bangtelindo) dan Konstruksi \& Konsultasi Fas.Tel.

Adapun jumlah pegawai dalam kantor PT. Telkom Divre VII Kota Makassar di tinjau dari status pegawainya yakni sebanyak 103 pegawai. Terdiri dari pegawai telkom regional sebanyak 6 orang, Pegawai tetap sebanyak 17 orang, pegawai kemitraan sebanyak sebanyak 20 orang, dan pegawai outsourcing sebanyak 60 orang.

Ditinjau dari segi pendidikan pegawai di kantor PT. Telkom Divre VII
Kota Makassar yakni dari jenjang pendidikan SLTA/SMK sebanyak 28, D-III sebanyak 17 orang, S-1 sebanyak 51 orang, dan S-2 sebanyak 1 orang.

Mewujudkan visi dan misi dalam sebuah perusahaan maka setiap pegawai atau karyawan sangat di tuntut untuk memiliki kualitas kerja yang baik dalam menyelesaikan pekerjaan dan tanggung jawabnya. Begitu pula dengan ketepatan waktu untuk melatih kedisiplinan setiap pegawai yang ada di dalam sebuah perusahaan.

Berkreasi atau memiliki kreatifitas diri sangat di tuntut setiap pegawai memiliki inisiatif ketika melakukan sebuah pekerjaan. Tidak lepas pula dengan kemampuan setiap pegawai untuk memiliki keahlian dalam hal tanggung jawabnya selaku pekerja. Begitu pula dengan komunikasi harus bisa terjalin dengan baik sehingga dalam hal penyampaian informasi dapat berjalan dan sesuai dengan prosedur perusahaan yang telah di tetapkan.

Maka dari itu dalam menjamin hak-hak dasar dan perlakuan tanpa diskriminasi pekerja 
diterapkan peraturan perundang-undangan perlindungan bagi pekerja yaitu UU No. 13 Tahun 2003 Tentang Ketenagakerjaan serta Peraturan Pelaksana dari perundangundangan di bidang Ketenagakerjaan.

Mewujudkan

peningkatan

kesejahteraan pekerja maupun keluarganya. Begitu pula diatur dalam konstitusi tertuang pada Pasal 27 ayat (2) UUD Tahun 1945 berbunyi "Tiap-tiap warga Negara berhak atas pekerjaan dan penghidupan yang layak bagi kemanusiaan”, dan Pasal 33 ayat (1) yang menyatakan bahwa" Perekonomian merupakan suatu usaha bersama atas kekeluargaan”.

$$
\text { Kualitas Kerja Menurut }
$$

Sedarmayanti (2011) mengemukakan bahwa ada tida indicator yang menjadi tolak ukur atas kualitas kerja pegawai yakni : a) Hasil kerja pegawai yang di peroleh, b) Kesesuaian hasil kerja dengan tujuan organisasi, c) Manfaat hasil kerja. Menjalankan roda perusahaan dengan baik yakni salah satu faktor pendukung penunjang pencapaian visi misi dalam sebuah perusahaan adalah kualitas kerja. Dengan memiliki kualitas kerja yang baik tentu akan menjadi salah satu tolak ukur dalam mencapai tujuan suatu perusahaan. Seperti halnya yang dilakukan oleh bapak N.M selaku General Manejer PT. Telkom Akses Divre VII Kota Makassar.

"Kalau kita berbicara mengenai kualitas kerja yang ada di kantor PT. Telkom Akses Divre VII Kota Makassar ini tentu sudah bagus. Dikarena hasil kerja dari setiap pegawai sudah cukup untuk membantu perusahaan dalam hal mencapai target. Khususnya dalam hal pemasangan wifi, setiap pegawai sudah menjalankan tugas yang di berikan oleh perusahaan. Di lihat dari jumlah pemasangan yang sudah melewati target di kantor PT. Telkon Akses. Dengan kata lain tanggung jawabnya sebagai pegawai sudah di tunaikan. (Wawancara dengan Bapak N.M, Pada Tanggal 23 Juli 2018).

Ketepatan waktu yang menjurus kepada kedisiplinan seluruh pegawai di kantor PT. Telkom Divre VII Kota Makassar yakni jam masuk kerja dan jam pulang kerja setiap pegawai. Kedisiplinan pegawai adalah suatu pengertian yang didalamnya 
mengandung norma etika, sosial dan scientific. Kedisiplinan pegawai dalam suatu bidang kerja perusahaan yang di pertanggung jawabkan itu adalah baik, dapat diterima, di setujui oleh pihak perusahaan, dan mengandung kebenaran atas dasar peraturan yang telah di tetapkan dalam sebuah perusahaan. Jadi dalam hal ini kedisiplinan pegawai mengandung makna yakni kesanggupan pegawai dalam hal memegang tanggung jawab atas peraturatur yang di sepakati dalam sebuah perusahaan.

Seperti halnya yang telah diungkapkan oleh bapak B.J selaku Mgr Financedi kantor PT. Telkom Akses Divre VII Kota Makassar.

"bahwa dalam hal ketepatan waktu setiap pegawai di kantor PT. Telkom Divre Kota Makassar memiliki perbedaan dalam hal jam masuk dan pulang kerja setiap pegawai. Yang dimana pegawai tetap harus lebih dulu masuk kantor ketimbang pegawai outsourcing. Dilihat dari status pegawai tetap yang senantiasa tunduk dan patuh akan peraturan yang di buat oleh perusahaan. Berbeda halnya dengan pegawai outsourcing yang hanya di perkerjakan dalam sebuat perusahaan untuk membantu perusahaan dalam menyelesaikan visi misinya." (Wawancara, bapak B.J Tanggal 23 Juli 2018).

Inisiatif adalah dorongan untuk mengidentifikasi masalah atau peluang dan mampu ambil tindakan nyata untuk menyelesaikan masalah atau menangkap peluang saat kita mempunyai dorongan sekecil apapun itu untuk mengidentifikasi masalah atau peluang maka kita sudah mempunyai inisiatif, walaupun dalam kadar yang rendah.

Menurut Sedarmayanti, 2009 ada 2 indikator dalam inisiatif yakni a) Pemberian ide/ gagasan dalam berorganisasi, b) Tindakan yang dilakukan untuk menyelesaikan permasalahan yang di hadapi. Oleh karena itu untuk mampu melatih kemampuan atau inisatif diri setiap pegawai tentu setiap perusahaan harus bisa memberikan kebebasan berfikir pada setiap pegawai untuk mengembangkan keterampilan yang di miliki dalam hal pemberian ide-ide baru atas dasar pemikiran setiap pegawai. 
Kolaborasi: Jurnal Administrasi Publik, Desember 2018 Volume 4 Nomor 3

Menurut Siagian salah satu aspek dari pertumbuhan dan pemeliharaan citra birokrasi yang positif adalah upaya yang sistematis, programatik, dan berkesinambungan dalam peningkatan kemampuan kerja birokrasi termasuk keahlian atau kemampuan sumber daya manusia.

Oleh karena itu sebagai birokrasi dituntut adanya aparatur yang kapabilitas yaitu sumber daya manusia yang bekerja dengan efisien, efektif, dan produktif. Kemampuan adalah perpaduan antara teori dan pengalaman yang di peroleh dalam praktek di lapangan, termasuk peningkatan kemampuan menerapkan teknologi yang tepat dalam rangka peningkatan produktivitas kerja.

Komunikasi adalah suatu proses pertukaran informasi baik melalui media massa, media cetak maupun melalui interaksi yang di lakukan oleh satu individu dengan individu lain secara langsung. Dalam organisasi komunikasi merupakan suatu hal yang urgen dalam artian komunikasi sangat menunjang pencapaian tujuan organisasi. Setiap anggota dalam sebuat organisasi sangat di tuntut untuk menjalin komunikasi yang baik antara individu satu dengan individu yang lain.

Berdasarkan hasil pengamatan peneliti dilapangan bahwa di kantor PT. Telkom Akses Divre VII Kota Makassar, terdapat indikator pendukung terkait kinerja pegawai outsouring seperti kualitas kerja, ketepatan waktu, inisiatif, kemampuan, dan komunikasi. Dalam hal kualitas kerja pegawai masih memiliki perbedaan berdasarkan status pegawai maupun kesadaran diri setiap pegawai. Demikian juga ketepatan waktu, dimana setaip pegawai cenderung tidak memiliki karakteristik kedisiplinan yang sama. Terkait dari inisiatif, kantor telah memberikan kebebasan dalam hal menggali potensi setiap pegawai untuk menuangkan ide-idenya dalam pencapaian tujuan perusahaan.

Kemampuan tentu semua pegawai sudah mampu menjalankan tugas dan tanggung jawabnya sebagai pegawai. Dan komunikasi yang terjalin dengan baik di kantor PT. Telkom Akses Divre VII Kota Makassar sudah baik di lihat dari 
penyampaian informasi yang mampu sampai di telinga semua pegawai.

\section{KESIMPULAN}

Berdasarkan hasil penelitian di Kantor PT. Telkom Akses Divre VII Kota Makassar mengenai kinerja pegawai masih baik di lihat dari hasil kerja setiap pegawai berdasarkan prosedur yang sudah di tetapkan oleh perusahaan.

Berdasarkan hasil wawancara dengan informan dapat di ketahui bahwa di kantor PT. Telkom Akses Divre VII Kota Makassar masih memiliki beberapa hambatan dalam hal mencapai kinerja yang unggul dalam sebuah perusahaan. Dari segi sumber daya manusia, dimana pegawai outsourcing merasa iri atas dasar pembagian kerja yang di berikan perusahaan. Hal inilah yang dapat melatar belakangi kinerja dalam sebuah perusahaan akan menurun.

Hal ini harus menjadi perhatian khusus bagi kantor Telkom Akses untuk bisa segera membenahi situasi yang kurang ada di dalam ruang lingkup kerja perusahaan.
Sebab kita ketahui bersama, kinerja pegawai merupakan kunci dari pencapaian visi dan misi dalam suatu perusahaan. Kondisi budaya organisasi sangat berpengaruh besar terhadap manajemen kinerja pegawai di kantor PT. Telkom Akses Divre VII Kota Makassar.

\section{DAFTAR PUSTAKA}

Dharma, Surya. (2009). Manajemen Kinerja Falsafah Teori dan Penerapannya.Yogyakarta: PustakaPelajar.

Hasibuan, Malayu S.P. 2009. Manajemen: Dasar, Pengertian, dan Masalah Edisi Revisi. Jakarta: Bumi Aksara.

Khairani. 2016. Kepastian Hukum Hak Pekerja Outsourcing. Jakarta: PT Raja Grafindo Persada

Mangkunegara, A.Anwar Prabu. 2011. Evaluasi Kinerja SDM. Cetakan Ketiga. Bandung: Penerbit Refika Aditama.

Manullang, M. 2012. Dasar-Dasar Manajemen Bagi Pimpinan Perusahaan. Jakarta: Gajah Mada Press

Sedarmayanti. 2009. Reformasi Administrasi Publik, Reformasi Birokrasi, dan Kepemimpinan Masa Depan (Mewujudkan Pelayanan Prima dan Kepemimpinan yang Baik). Bandung: Refika Aditama 
Kolaborasi: Jurnal Administrasi Publik, Desember 2018 Volume 4 Nomor 3

Sugiyono. 2015. Metode Penelitian Kuantitatif, Kualitatif, Dan R\&D. Bandung : Alfabeta.

UU Ketenagakerjaan Nomor 13 Tahun 2003 (pasal 64, 65, dan 66).

Keputusan Menteri Tenaga Kerja RI No/KEP.101/MEN/VI/2004 Tentang Tata

Cara Perijinan Perusahaan Jasa Pekerjal Buruh.

PT. Telekomukasi Indonesia, tbk, 2016. Company Profile. www.telkom.co.id. Di akses pada 24 Maret 2018 Jam 20.45 WIB. 